\title{
THE QUALITY OF MANAGERS IN CENTRALIZED VERSUS DECENTRALIZED ORGANIZATIONS*
}

\author{
RaAJ K. Sah and Joseph E. STIGLitz
}

A central task of the leadership of any organization is the choice of its successors and subordinates. Corporate presidents spend a significant part of their time selecting upper management. Tenured faculty sometimes spends months deciding whether particular individuals should be admitted into their ranks. The effort and contentiousness which often go into this process suggests that it has important consequences for the organization. It is recognized that there are large differences in individuals' abilities and that the abilities of those in leadership inevitably affect the performance and survival of the organization.

Our objective here is to examine how the centralization or decentralization of decision-making authority affects the quality of the managers who are actually selected. This question is naturally dynamic because the quality of current managers is not only influenced by that of past managers, but it, in turn, affects the quality of future managers.

We consider stylized economies consisting of an arbitrary number of hierarchies (organizations) of different sizes. The size of a hierarchy is the number of managers within the hierarchy, one of whom is the hierarch (the boss) and others are subordinates. The current hierarch appoints his own successor and those of his subordinates, but has no influence on any other hierarchy. (This assumption exaggerates somewhat the typical asymmetry of authority between the hierarch and the subordinates.) Our definition of a "more" or "less" centralized economy is intuitive: an economy is more centralized if it has a larger proportion of the total number of managers in larger hierarchies.

Our main result is that there is a greater variability (over time) in the steady-state quality of managers in a more centralized economy. This is because highly capable decision-makers have greater beneficial effects on the managerial choices in a more centralized economy. By the same token, highly incapable managers placed in the same positions have greater deleterious effects.

*We thank Roger Guesnerie, Jacques Crémer, and an anonymous referee for helpful comments and the National Science Foundation and the Olin Foundation for support.

( 1991 by the President and Fellows of Harvard College and the Massachusetts Institute of Technology.

The Quarterly Journal of Economics, February 1991 
The overall effect of a greater centralization, therefore, is to induce a greater variability, in the economy's managerial quality.

A natural next question is what is the relationship between the degree of centralization and the economy's output. The answer depends on, among other things, the nature of the relationship between managers' abilities and organizational output. We have investigated in detail a simple case in which managers choose projects in addition to their successors and subordinates.

\section{Managerial Quality}

There are two types of managers: those with high and those with low abilities to select managers; they are referred to as "good" and "bad" managers, respectively. If a high-ability manager selects a future manager, he (she) will select a high-ability manager with probability $q_{1}$, and a low-ability manager with probability $1-q_{1}$. The corresponding probabilities for a low-ability manager are $q_{2}$ and $1-q_{2}$. We assume that $1>q_{1}>q_{2}>0$; that is, while neither type of manager is perfect, each type has some ability to select high-ability managers. ${ }^{1}$

Let $n_{M}(s)$ denote the number of hierarchies of size $M$ in economy $s$, where $M \geq 1$. Let $N(s)=\Sigma_{M} M n_{M}(s)$ denote the total number of managers in economy $s$. Then, according to our definition, economy $s^{\prime}$ is more centralized than $s$, if $N(s)=N\left(s^{\prime}\right)=$ $N$, and if

$$
\sum_{M \leq J} M n_{M}(s) \geq \sum_{M \leq J} M n_{M}\left(s^{\prime}\right),
$$

for all $J \geq 1$, and the strict inequality holds in (1) for at least one $J$. That is, if the proportions of the total number of managers in an economy who are in hierarchies of different sizes are viewed as a discrete probability density function, then the economy $s^{\prime}$ is more centralized than $s$ if this density function in $s^{\prime}$ is a first-order stochastic improvement over that in $s$. For later use, define the average size of a hierarchy in economy $s$ as

$$
h(s)=\sum_{M} M^{2} \frac{n_{M}(s)}{N} .
$$

1. We treat $q$ 's as exogenous parameters. In another context (namely, the effect of homogeneous individuals' fallibility concerning project choice on organizational performance), analogous probabilities are endogenized in Sah and Stiglitz [1986a]. The role of fallibility under alternative organizational forms such as committees, hierarchies, and polyarchies is analyzed in Sah and Stiglitz [1988]. See Sah [1991] for an overview. 
It is obvious then that the average size of a hierarchy is larger in a more centralized economy. That is,

$$
h(s)<h\left(s^{\prime}\right) .
$$

Now consider a hierarchy of size $M$ in isolation from all other constituents of the economy. The random variable $m$ denotes the number of good managers. Within the present hierarchy, $m$ assumes values from 0 to $M$. Let $g(m \mid M)$ denote the steady-state density of $m$ in this hierarchy. Then,

$$
g(m \mid M) \equiv \sum_{k=1}^{2} z_{k} b\left(m, M, q_{k}\right),
$$

where

$$
z_{1}=q_{2} /(1-Q), \quad z_{2}=1-z_{1}=\left(1-q_{1}\right) /(1-Q),
$$

$\boldsymbol{Q} \equiv q_{1}-q_{2}$, and $b\left(m, M, q_{k}\right) \equiv\left({ }_{m}^{M}\right) q_{k}^{m}\left(1-q_{k}\right)^{M-m}$ is the binomial density of $m$ successes out of $M$ trials when $q_{k}$ is the probability of each success.

The derivation of (4) is highly intuitive. The succession process depends critically on the hierarch because the subordinates do not influence it. $z_{1}$ is the (steady-state) probability that the hierarch is a good manager, and $z_{2}$ is the probability that the hierarch is a bad manager. ${ }^{2}$ Further, the binomial density $b\left(m, M, q_{1}\right)$ is the probability that $m$ good managers are chosen when the hierarch is good, and $b\left(m, M, q_{2}\right)$ is the corresponding probability when the hierarch is bad. Straightforward combination of these probabilities yields (4).

Next, let $\lambda(M)$ and $v(M)$, respectively, denote the mean and the variance of the number of good managers in a hierarchy of size $M$. Then, (4), (5), and the standard properties of the binomial variate yield

$$
\lambda(M)=M z_{1}, \quad \text { and } \quad v(M)=M^{2} z_{1} z_{2} Q^{2}+M \sum_{k=1}^{2} z_{k} q_{k}\left(1-q_{k}\right) .
$$

To analyze the economy $s$ as a whole, let $\Lambda(s)$ and $V(s)$, respectively, denote the mean and the variance of the number of

2. In the steady state, $z_{1}=z_{1} q_{1}+z_{2} q_{2}$, because $q_{1}$ is the probability of selecting a good manager as the next period's hierarch if the current hierarch is good, whereas $\mathrm{q}_{2}$ is the corresponding probability if the current hierarch is bad. Using $z_{2}=1-z_{1}$, the preceding expression yields (5). 
good managers in this economy. Since the mean or the variance of a sum of independent random variables is the sum of their respective means or variances, (2) and (6) yield

$$
\Lambda(s)=N z_{1}, \text { and } V(s)=\left[z_{1} z_{2} Q^{2} h(s)+\sum_{k=1}^{2} z_{k} q_{k}\left(1-q_{k}\right)\right] N .
$$

It follows that the number of good managers in a more centralized economy has the same mean but a higher variance.

Expressions (2) and (7) yield an additional result. Even when two economies are not comparable, in the sense that one of them is more centralized based on our definition, it is still the case that an economy with a larger average size of a hierarchy has a larger variance in the number of good managers.

Next, consider the distribution of good managers. If $\pi(m \mid s)$ denotes the probability density associated with the state in which there are $m$ good managers in economy $s$, then $\pi(m \mid s)$ for various $m$ 's are obtained from the convolution of the densities given by (4). For instance,

$$
\pi(0 \mid s)=\Pi_{M}\left\{\sum_{k=1}^{2} z_{k} b\left(0, M, q_{k}\right)\right\}^{n_{M}(s)}
$$

and

$$
\pi(N \mid \mathrm{s})=\Pi_{M}\left\{\sum_{k=1}^{2} z_{k} b\left(M, M, q_{k}\right)\right\}^{n_{M}(s)}
$$

denote the probabilities associated with the polar states where, respectively, none of the managers is good, and none of the managers is bad. It is easy to verify that $\partial \pi(0 \mid s) / \partial q_{k}<0$, and $\partial \pi(N \mid s) / \partial q_{k}>0$, for $k=1$ and 2 . That is, if individual managers are more capable in choosing future managers, then the probability that an economy has all high-ability managers is higher, and the probability that the economy has all low-ability managers is lower. This is what one would expect.

A general comparison of $\pi(m \mid s)$ and $\pi\left(m \mid s^{\prime}\right)$ is difficult, given the complexity of expressions such as (8) and (9). To obtain additional insights, therefore, we compare two economies with two managers each. The decentralized economy $s$ has two hierarchies, each of size one (that is, $n_{1}(\mathrm{~s})=2$, and $n_{M}(s)=0$ for $M \neq 1$ ). The centralized economy $s^{\prime}$ has one hierarchy of two managers (that is, $n_{2}\left(s^{\prime}\right)=1$, and $n_{M}\left(\mathrm{~s}^{\prime}\right)=0$ for $\left.M \neq 2\right)$. Values of the $\pi$ 's can then be 
explicitly calculated, using expressions such as (8) and (9), as

$$
\begin{gathered}
\pi(0 \mid s)=\frac{\left(1-q_{1}\right)^{2}}{a}, \pi(1 \mid s)=2 q_{2} \frac{1-q_{1}}{a}, \\
\text { and } \pi(2 \mid s)=\frac{q_{2}^{2}}{a}
\end{gathered}
$$

$$
\pi\left(0 \mid s^{\prime}\right)=\left(1-q_{1}\right) \frac{1-q_{2}(1+Q)}{b}
$$

$$
\pi\left(1 \mid s^{\prime}\right)=2 q_{2}\left(1-q_{1}\right) \frac{1+Q}{b}, \quad \text { and } \pi\left(2 \mid s^{\prime}\right)=q_{2} \frac{q_{2}+q_{1} Q}{b} ;
$$

where $a \equiv(1-Q)^{2}$, and $b \equiv 1-Q$. From (10) and (11),

$$
\sum_{j \leq m} \sum_{i \leq j}\left\{\pi\left(i \mid s^{\prime}\right)-\pi(i \mid s)\right\} \geq 0
$$

for all $m$, and the strict inequality holds for at least one $m$. Equivalently, $\pi\left(m \mid s^{\prime}\right)$ is a mean-preserving spread of $\pi(m \mid s)$. Thus, a greater centralization induces a mean-preserving spread in the number of good managers. ${ }^{3}$

Finally, consider an alternative approach that illustrates, in the simple case in which there are two managers in ecomony $s$ as well as in $s^{\prime}$, our earlier general result that the number of good managers has a higher variance in a more centralized economy. ${ }^{4}$ Denote the steady-state quality of the $i$ th manager by the random variable $X_{i}$, where $i=1$ and 2 , and $X_{i}$ is 1 or 0 depending on whether the manager is good or bad. Then, $\operatorname{Pr}\left\{X_{i}=1\right\}=z_{1}$, and $\operatorname{Pr}\left\{X_{i}=0\right\}=z_{2}$, as described in (5). It is clear that these probabilities do not depend on the economy to which the manager belongs. Thus, the economy does not affect the moments of $X_{i}$ (including its variance); it only affects the correlation among these variables. Note that $V(s) \equiv \operatorname{var}\left(X_{1}+X_{2} \mid s\right)=\operatorname{var}\left(X_{1}\right)+\operatorname{var}\left(X_{2}\right)+2 \operatorname{cov}\left(X_{1}, X_{2} \mid s\right)$. Now, it is apparent and can be easily established that $\operatorname{cov}\left(X_{1}, X_{2} \mid s\right)=$ 0 , because the two managers are chosen by two different hierarchs in economy $s$, and that $\operatorname{cov}\left(X_{1}, X_{2} \mid s^{\prime}\right)>0$, because the two managers are chosen by the same hierarch in economy $s^{\prime}$. Thus, $V\left(s^{\prime}\right)>V(s)$.

3. This result, (12), is likely to hold regardless of the size $N$ of the system. Partial support for this conjecture comes from (8) and (9) which yield (see an earlier version of the present paper [1986b]) that $\pi\left(m \mid s^{\prime}\right)>\pi(m \mid s)$, for $m=0$ and $N$. That is, the probability that all managers are good, or that all managers are bad, is higher in a more centralized economy.

4. This approach was suggested by a referee. 


\section{MANAGERIAL OUtPUT}

The relationship between the quality of managers and the output or the performance of an organization is complicated. It depends not only on the distribution of ability and on the tasks that managers perform, but also on the positive and negative externalities that good and bad managers exert on one another. In this section we examine these aspects using the simple model, described in a part of the last section, in which there are only two managers in the decentralized as well as in the centralized economy.

First, consider the case where the expected output of both economies is the same if they have the same number of good managers. Then, from the observation made earlier that the distribution of the number of good managers in the centralized economy is a mean-preserving spread of the corresponding distribution in the decentralized economy, it follows that the output in the centralized economy is smaller than that in the decentralized economy if the output is concave in the number of good managers. The opposite is the case if the output is convex in the number of good managers.

The relative performance of the centralized economy is further weakened if the comparison is based not on the expected output but on the expected utility of the output, and if the utility displays some risk aversion. In fact, even when output is convex in the number of good managers, if the utility is sufficiently concave in output, the expected utility will be higher in the decentralized economy.

In the rest of this section we analyze a specific example with explicit managerial tasks. Managers select projects and future managers. For simplicity, we assume that there are only two types of projects: good projects, yielding an (expected net) profit $x$; and bad projects, yielding a profit $-x$. Half the projects are good; half are bad. Bad managers are assumed not to have discriminating ability; they randomly accept a fraction $p_{2}$ of the projects. Good managers are better at choosing future managers as well as projects; they accept a good project with probability $p_{1}^{1}$ and a bad project with probability $p_{1}^{2}$, where $p_{1}^{1}>p_{2}>p_{1}^{2}$. The fraction of projects that a good manager accepts is $p_{1} \equiv\left(p_{1}^{1}+p_{1}^{2}\right) / 2$.

In economy $s^{\prime}$ a project is accepted only if both managers accept it. In contrast, in economy $s$ a project is accepted if either of the two independent managers accept it. Thus, the "decentralized" economy is more decentralized in the selection of successors as well 
as of projects. ${ }^{5}$ Let $Y(m \mid s)$ denote the profit of economy $s$ if there are $m$ good managers. Then, ${ }^{6}$

$$
\begin{aligned}
Y(0 \mid s) & =0, \quad Y(1 \mid s)=1-p_{2}, & \text { and } \quad Y(2 \mid s) & =2\left(1-p_{1}\right) . \\
Y\left(0 \mid s^{\prime}\right) & =0, \quad Y\left(1 \mid s^{\prime}\right)=p_{2}, & & \text { and } \quad Y\left(2 \mid s^{\prime}\right)=2 p_{1} .
\end{aligned}
$$

The steady-state profit of economy $s$ is $Y(s)=\Sigma_{m} \pi(m \mid s) Y(m \mid s)$. $\Delta Y=Y(s)-Y\left(s^{\prime}\right)$ is the difference between the profits of the two economies. Then, (10), (11), (13), and (14) yield

$$
\Delta Y=2 \pi(2 \mid s)\left(1-2 p_{1}\right)+\pi(1 \mid s)\left(1-2 p_{2}\right)-2 \delta\left(p_{1}-p_{1}\right)
$$

where $\delta=q_{2}\left(1-q_{1}\right) Q^{2} /(1-Q)^{2}>0$. Now consider the case where both types of managers accept the same fraction of projects (that is, $p_{1}=p_{2}=p$ ). Then, the screening of projects by managers is "tight" or "slack" depending on whether $p$ is smaller or larger than one half. It follows from (15) that the profit of the decentralized economy is larger than that of the centralized economy, if the screening of projects by managers is tight, while it is smaller, if the screening of projects by managers is slack.

UNIVERSITY OF CHICAGO AND YALE UNIVERSITY

STANFORD UNIVERSITY

\section{REFERENCES}

Sah, Raaj K., "Fallibility in Human Organizations and Political Systems," Journal of Economic Perspectives (1991), forthcoming. , and Joseph E. Stiglitz, "The Architecture of Economic Systems: Hierarchies and Polyarchies," American Economic Review, LXXVI (1986a), 716-27.

, and ___, "Managerial Quality in Centralized versus Decentralized Economic Systems," Economic Growth Center Discussion Paper 515, Yale University, $1986 \mathrm{~b}$.

and "Committees, Hierarchies and Polyarchies," Economic Journal, XCVIII (1988), 451-70.

5. We have assumed here that the centralization of decision-making authority in one dimension is correlated with that in another dimension.

6. In the expressions for the $Y$ 's, we suppress a constant, $T x\left(p_{1}^{1}-p_{1}^{2}\right) / 2$, where $T$ is the number of available projects. It is assumed that, in economy $s$, half of the projects initially go to each of the two managers, that those rejected by one manager go to the other, and that the same project is not reviewed more than once by each manager. Thus, for example, when economy $s$ has two good managers, the acceptance probabilities for a good project and a bad project are, respectively, $p_{1}^{1}\left(2-p_{1}^{1}\right)$ and $p_{1}^{2}\left(2-p_{1}^{2}\right)$. The profit is $Y(2 \mid s)=T x\left[p_{1}^{1}\left(2-p_{1}^{1}\right)-p_{1}^{2}\left(2-p_{1}^{2}\right)\right] / 2$, which is reexpressed as in (13). 